\title{
Laterally Spreading Tumor-like Early Cancer in Ileum
}

\author{
Kaho Yamasaki ${ }^{1}$, Kento Takenaka ${ }^{1}$ and Kazuo Ohtsuka ${ }^{2}$
}

Key words: small bowel, LST

(Intern Med 58: 885-886, 2019)

(DOI: 10.2169/internalmedicine.1836-18)

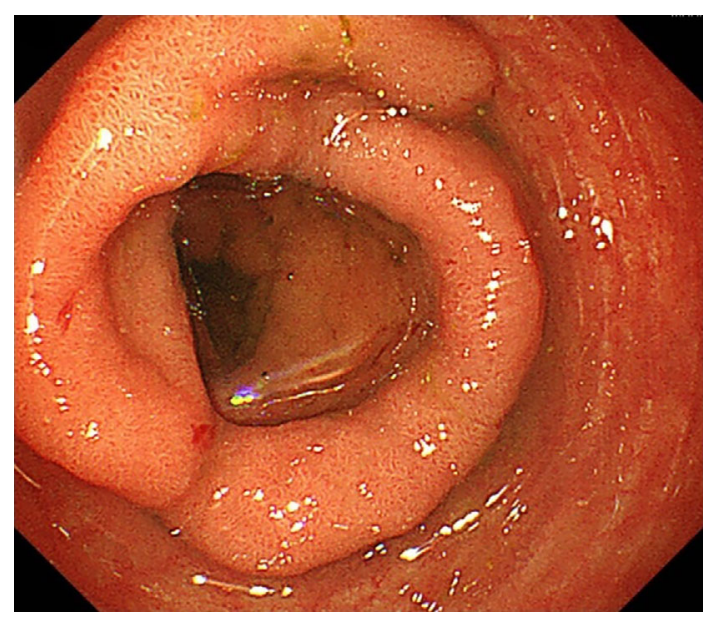

Picture 1.

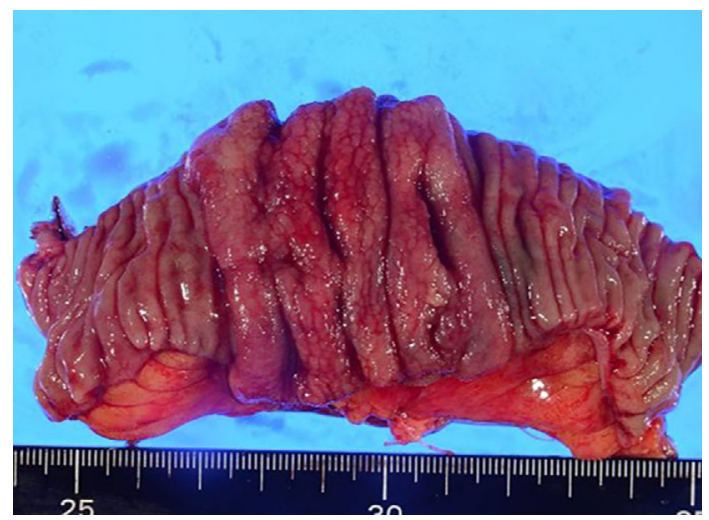

Picture 3.

An 84-year-old man with continuing iron deficiency anemia was referred to our hospital. Esophagogastroduodenoscopy and ileocolonoscopy showed no significant hemorrhagic lesions. The patient underwent retrograde balloonassisted enteroscopy (BAE). A laterally spreading tumor

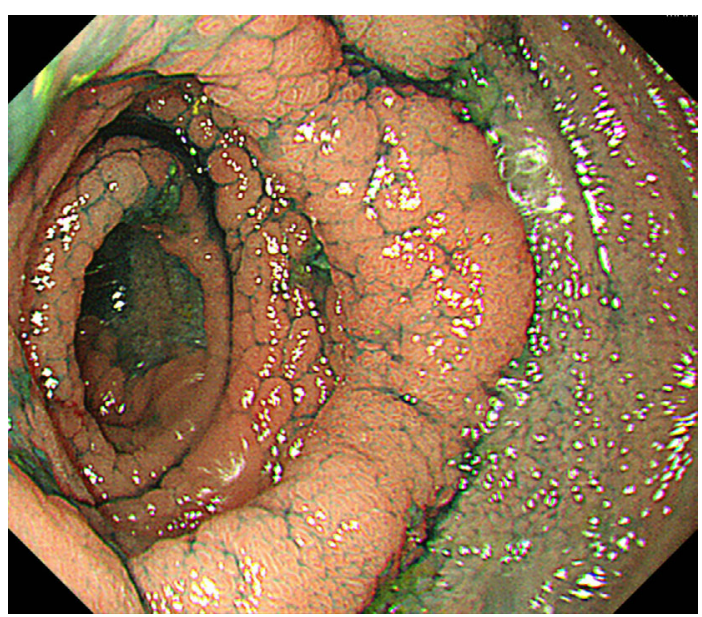

Picture 2.

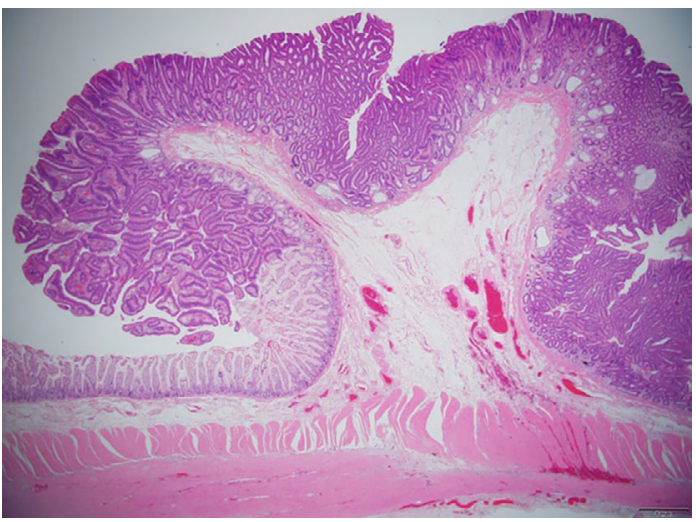

Picture 4.

(LST)-like tumor with an erythematous perimeter was detected in the ileum $60 \mathrm{~cm}$ from the ileocecal valve (Picture 1,2). An analysis of the biopsy specimen revealed a neoplastic lesion, and the tumor was surgically resected. The definitive diagnosis according to a pathologic analysis was

${ }^{1}$ Department of Gastroenterology and Hepatology, Tokyo Medical and Dental University, Japan and ${ }^{2}$ Department of Endoscopy, Tokyo Medical and Dental University, Japan

Received: July 16, 2018; Accepted: August 21, 2018; Advance Publication by J-STAGE: October 17, 2018

Correspondence to Kento Takenaka, ktakenaka.gast@tmd.ac.jp 
intramucosal adenocarcinoma with no adenomatous component and without vascular or lymphatic invasion (Picture 3,4$)$. LSTs are flat, elevated neoplastic lesions that normally occur in the colon and are considered to be early cancerous lesions (1). Small bowel (SB) cancer is extremely rare, comprising only $3 \%$ of all gastrointestinal tumors (2). SB cancers are usually diagnosed at an advanced stage, with circular SB stenosis as a presenting symptom. We herein report the first case of LST-like adenocarcinoma in the SB that was detected during BAE.

The authors state that they have no Conflict of Interest (COI).

\section{References}

1. Inoue $\mathrm{H}$, Kashida $\mathrm{H}$, Kudo $\mathrm{S}$, et al. The Paris endoscopic classification of superficial neoplastic lesions: esophagus, stomach, and colon. Gastrointest Endosc 58: S3-S43, 2003.

2. Sieqel RL, Miller KD, Jemal A. Cancer statistics 2016. CA Cancer J Clin 66: 7-30, 2016.

The Internal Medicine is an Open Access journal distributed under the Creative Commons Attribution-NonCommercial-NoDerivatives 4.0 International License. To view the details of this license, please visit (https://creativecommons.org/licenses/ by-nc-nd/4.0/).

(C) 2019 The Japanese Society of Internal Medicine Intern Med 58: 885-886, 2019 